\title{
Analysis on Risk Factors of BIM Application in Construction Project Operation and Maintenance Phase
}

\author{
Chenglong Yang, Liang Mao \\ School of Management, Sichuan University of Science and Engineering, Yibin, China \\ Email: 7993555780@qq.com
}

How to cite this paper: Yang, C. L., \& Mao, L. (2021). Analysis on Risk Factors of BIM Application in Construction Project Operation and Maintenance Phase. Journal of Service Science and Management, 14, 213-227.

https://doi.org/10.4236/jssm.2021.142013

Received: March 12, 2021

Accepted: April 25, 2021

Published: April 28, 2021

Copyright $\odot 2021$ by author(s) and Scientific Research Publishing Inc. This work is licensed under the Creative Commons Attribution International License (CC BY 4.0). http://creativecommons.org/licenses/by/4.0/

\begin{abstract}
There are various risk factors in the application of BIM. The reasonable management of risk factors can avoid unnecessary cost losses. Based on a large amount of literature, the article combed out the 17 risk factors that existed in the operation and maintenance phase, and revised it through expert interview method, and then obtained 11 risk factors. Semi-structured interviews were used to investigate the relationship between risk factors, and established Interpretative Structural Modeling (ISM) to analyze the hierarchical relationship of risk factors, and got two surface risk factors, five middle risk factors, and four deep risk factors. Finally, relevant improvement suggestions are put forward to eliminate or reduce the risk of using BIM in the operation and maintenance phase.
\end{abstract}

\section{Keywords}

Operation and Maintenance Phase, ISM, BIM, Risk Factor

\section{Research Background}

The report of the $19^{\text {th }}$ National Congress of the Communist Party of China pointed out that in order to vigorously transform and upgrade traditional industries and build a digital China, the construction industry has also ushered in a digital transformation with BIM as the core (Meng, 2017). Building Information Modeling (BIM) refers to the digital expression of physical and functional information of construction projects based on the concept of three-dimensional digital technology and information sharing. It can provide the entire life cycle of construction projects from conceptual design to final demolition. Decision support, its visualization, simulation, integration and other characteristics can real- 
ize the integrated management of all stages of the building from planning to operation and maintenance, which can greatly reduce design errors, improve construction efficiency, reduce costs, reduce waste and improve the efficiency of operation and maintenance management (Xu \& Xiong, 2014). In recent years, BIM has gradually been applied to construction projects and has been recognized by relevant operators. For example, the outer ring project of Zhengzhou Long For Financial Center (Yu et al., 2018), the Tianjian Tianjiao project in Futian District of Shenzhen (Liang, 2020), and the Baishishan Geological Museum in Baoding, Hebei have all adopted BIM technology to achieve good results (Zhu \& Fu, 2020). Through the use of BIM, these projects have solved many technical and management problems, improved the economic benefits of the project and shortened the project duration.

However, the application of new technologies will inevitably lead to new thinking and new methods that are different from traditional engineering. At the same time, it will bring corresponding challenges. The more advanced the technology concept, the higher the uncertainty and the higher the risk (Eastman et al., 2011). Correctly identifying and responding to risks reasonably are the key to ensuring the smooth advancement of BIM.

The paper is divided into six parts. The first part is the research background analysis and relevant literature review. After summarizing relevant literature, the risk factors are summarized, and then the BIM application interpretative structural modeling in the operation and maintenance stage is established and analyzed.

Then, based on the model, it puts forward corresponding measures to improve the application level of BIM in the operation and maintenance stage. Finally, it summarizes and analyzes the deficiencies of the article.

\section{Literature Review}

BIM technology originated in the United States, so the risk research process for the application of BIM abroad is far greater than that in China. Government agencies, related enterprises and scientific research institutions are actively promoting and participating in the research of BIM.

The risk factors that construction projects will face when using BIM technology are analyzed in detail (Bernstein \& Pitman, 2005), and he pointed out that only when information sharing and traditional business processes are changed can it be better applied to construction projects. A combination of questionnaire surveys and case studies is used (Azhar, 2011) obtained the benefits and risks brought by the application of BIM. Also, (Eadie et al., 2014) pointed out that factors such as technology, economy, organization, and related laws are the key factors that hinder the application of BIM. The above factors must be paid attention to and corresponding measures must be taken. Fuzzy Analytic Hierarchy Process and TOPSIS are used in combination (Taylan et al., 2014) to carry out risk assessment on engineering projects, and combines actual case studies. The research results show that the combination of the two methods is beneficial to 
the risk management of multi-objective decision-making. There are also some scholars in China who have studied the risks of applying BIM to the whole life cycle of buildings. Chinese scholar (Xu \& Xiong, 2014) analyzed the problems in the application of domestic BIM technology from a case study, and then summarized the risk factors that may arise in the process of BIM application. Also, (Wang, 2015) used grounded theory combined with actual project survey data to identify the risk factors of the application of BIM in engineering projects, applied DEMATEL method combined with expert experience to analyze risks, and proposed management and control strategies for risks from the perspective of project managers. The risk of architectural design companies using BIM technology is identified by grounded theory (Chen, 2012), and obtained five first-level risk indicators: technology selection, human resources, technology application process management, industry standards, and capital investment, using analytic hierarchy process and interpretative structural model completes the root cause analysis of risk factors. From the perspective of construction companies (Hu et al., 2018) used literature review and Delphi method to identify risk factors, built a structural equation model to obtain five first-level risk factors, and put forward corresponding points from the perspective of risk roots and risk reduction. Measures. Also, (Feng et al., 2019) and (Xie et al., 2018) constructed a BIM application risk evaluation system from the perspective of the owner, and proposed countermeasures for corresponding risks.

The management of the operation and maintenance phase of a construction project is called operation and maintenance management. Operation and maintenance management refers to the integration of personnel, equipment, technology and management processes, and reasonable planning, maintenance, repair, and emergency management of personnel and living spaces (Hu et al., 2015), Meet the basic needs of personnel at work. Operation and maintenance management based on BIM can get rid of the inefficiency of traditional operation and maintenance management, improve the accuracy of information required for management, and improve economic benefits.

At this stage, most of the research on the risk of BIM application in our country is focused on design (Chen, 2012), construction (Hu et al., 2018; Xu, 2020; Zhang et al., 2017), and cost (Yang, 2017). There is a lack of BIM application risk analysis in the operation and maintenance stage of construction projects, and from the perspective of the full life cycle of the construction project, the latter stage of construction occupies the vast majority of the entire life cycle of a building.

Therefore, not only the risk analysis of the application of BIM in the design and construction phases, but also the risk management of the application of BIM in the operation and maintenance phase of the construction project, will save the cost of the project in the later use process and produce more economic benefits (Tong \& Wang, 2014). Based on this background, the article identifies the application risks of BIM technology in the operation and maintenance phase of con- 
struction projects, analyzes the risk factors using expert interviews and interpretative structural modeling, and provides theoretical support for the application of BIM in the operation and maintenance phase.

\section{Identification of Risk Factors}

In view of the extensive research on the application of BIM at home and abroad in recent years, the article adopts the method of literature review to identify risk factors. Through the sorting and analysis of the retrieved articles, the literatures related to the risk factors of BIM application were selected and summarized, and the risk factors related to the operation and maintenance stage of the construction project were initially identified as shown in Table 1.

In order to facilitate modeling and analysis, the expert interview method is used to modify the risk factors initially identified. The factor of "lack of BIM related standards" is deleted, because with the development of domestic BIM technology in recent years, the country has issued some related standards on BIM, including building information model classification and coding standards and BIM application unified standards, etc., National standard. In addition, "The market popularity is not high." and "Poor social awareness." are integrated into one risk factor, "insufficient data security" and "model data interaction is poor" are combined into one factor. Combine the three factors of "the operator's initiative is poor, insufficient ability of managers, and insufficient competence of enterprise employees." into one factor. The "BIM model integrity" factor is also added. The integrity of the BIM model in the design and construction stages has a relatively important impact on the use of the operation and maintenance stage. In order to promote the application of BIM in the operation and maintenance phase, it is necessary to introduce BIM from the initial planning stage of the project, and the corresponding integration of various participants from the planning stage of the project, which raises a higher level of integrity of the model Requirements.

By revising the risk factors, combined with the description and definition of the risk factors, the risk factor table of BIM technology application in the operation and maintenance phase of the construction project is shown in Table 2.

\section{BIM Application Risk Model Construction in the Operation and Maintenance Phase}

The study uses the Interpretative Structural Modeling (ISM) to determine the hierarchical relationship of risk factors. Interpretative structural modeling is a method developed by Professor WARFIELD in the United States in 1973 to analyze the structural problems of complex economic systems (Wang et al., 2019; Qin et al., 2016). It is an analysis method widely used in modern systems engineering. The method is constructed based on the binary relationship between system elements. The corresponding hierarchical structure model can vividly express the structural relationship between elements. 
Table 1. Preliminary identification of related risk factors in the operation and maintenance phase.

\begin{tabular}{ll}
\hline Risk factors & Risk description \\
\hline $\begin{array}{l}\text { The market popularity is not } \\
\text { high. }\end{array}$ & $\begin{array}{l}\text { The market popularity of BIM in the operation and maintenance stage } \\
\text { is not high, and the industry experience is insufficient }\end{array}$ \\
$\begin{array}{ll}\text { The change of management } \\
\text { mode. }\end{array}$ & $\begin{array}{l}\text { From the traditional two-dimensional management mode to the use of } \\
\text { BIM model technology for management, the management does not } \\
\text { adapt to the new mode. }\end{array}$
\end{tabular}

Short-term workload increase. A large amount of manpower and material resources must be invested

Insufficient competence of enterprise employees.

The domestic BIM operation and maintenance system and management platform are insufficiently mature.

The operator's initiative is poor.

Lack of driving force for enterprise reform.

Uncertain returns.

Lack of BIM related
standards.

Model data interaction is poor.

Model legal responsibility is not clear.

Poor social awareness.

Technical applicability is not high.

BIM is difficult to use in the operation and maintenance stage.

Lack of BIM talents.

Insufficient data security.

Insufficient ability of managers. in the early stage of the project before it can be used for the management of the operation and maintenance stage.

\section{Related literature sources}

(Wang, 2015; Tian, 2018; Chen et al., 2017; Liu et al., 2018)

(Eadie et al., 2014; Zhang et al., 2017; Chen et al., 2017; Guo, 2015; Li et al., 2018; Zhang et al., 2016)

(Li, 2016; Wang, 2015; Guo, 2015)

Employees have insufficient knowledge and ability structure of BIM and (Zhang et al., 2017; Liu et al., 2018; Xu et lack of relevant knowledge.

al., 2014; Li et al., 2018; Chien et al., 2014)

The domestic BIM operation and maintenance stage software platform is immature at this stage and cannot meet the actual requirements

(Li, 2016; Tian, 2018; Hu et al., 2018; Tong \& Wang, 2014; Hu et al., 2015)

Enterprise employees are accustomed to the traditional work mode and avoid new technologies.

(Chen et al., 2017; Liu et al., 2018; Hu et al., 2018; Xu et al., 2014; Guo, 2015)

Lack of investment and determination to adopt new technologies

(Li, 2016; Tian, 2018; Zhang et al., 2016)

Increased short-term costs, long payback periods, high short-term

(Zhang et al., 2017; Liu et al., 2018; Hu et investment costs for BIM technology's software and hardware, and high al., 2018; Xu et al., 2014; Guo, 2015; Li et personnel training and recruitment costs

al., 2018)

Lack of corresponding guidelines and model delivery standards in China.

Model interaction between different software, different stages, and different users is difficult, and it is easy to cause data loss.

(Tian, 2018; Chen et al., 2017; Liu et al., 2018; Li et al., 2018; Feng et al., 2019)

(Azhar, 2011; Xu \& Xiong, 2014; Xu et al., 2014; Guo, 2015; Feng et al., 2019; Hu et al., 2015)

(Zhang et al., 2017; Liu et al., 2018; Li et al., 2018; Eastman et al., 2011; Azhar, 2011)

(Li, 2016; Chen et al., 2017; Zhang et al., 2016; Feng et al., 2019)

(Hu et al., 2018; Xu et al., 2014; Zhang et al., 2016; Xie et al., 2018)

BIM originated from abroad, and does not match the develop China's construction industry, and the degree of applicability is not high.

BIM technology is more difficult to use in the operation and maintenance stage, which is quite different from the traditional operation and maintenance management mode.

(Li, 2016; Wang, 2015; Hu et al., 2018; Xu et al., 2014; Guo, 2015)

Lack of talents familiar with BIM software and concepts, and lack of talents mastering BIM operation and maintenance management.

(Wang, 2015; Zhang et al., 2017; Liu et al., 2018; Hu et al., 2018; Guo, 2015; Ding \& Wang, 2016)

BIM model information storage security, data interaction security, especially information security of public infrastructure.

(Zhang et al., 2017; Xu et al., 2014; Guo, 2015; Li et al., 2018; Ding \& Wang, 2016; Feng et al., 2019)

(Chen et al., 2017; Hu et al., 2018; Zhang et al., 2017)

Note: Data in the table are summarized from relevant CNKI literature. 
Table 2. Risk factors of BIM application in operation and maintenance phase.

\begin{tabular}{lll}
\hline Primary risk factor & Secondary risk factor & Risk description \\
\hline $\begin{array}{l}S_{1} \text { Preliminary workload } \\
\text { increased. }\end{array}$ & $\mathrm{S}_{1-1}$ Short-term workload increase. & $\begin{array}{l}\text { A large amount of manpower and material resources need to be } \\
\text { invested in the early planning, design, and construction phases of the } \\
\text { construction project before it can be used for the management of the } \\
\text { operation and maintenance phase, resulting in an increase in the } \\
\text { preliminary workload. }\end{array}$ \\
&
\end{tabular}

$S_{2}$ Has a long payback period and $S_{2-1}$ Uncertain returns. uncertain returns.

\section{$\mathrm{S}_{3}$ Companies lack initiative in BIM applications.}

$\mathrm{S}_{4}$ The overall market awareness is not mature enough, and industry experience is lacking.

$\mathrm{S}_{5}$ Employees are inadequate in using BIM and have poor initiative.

\begin{tabular}{|c|c|}
\hline $\mathrm{S}_{6}$ Lack of BIM-related talents. & $\mathrm{S}_{6-1}$ Lack of BIM talents. \\
\hline $\begin{array}{l}S_{7} \text { Operation and maintenance } \\
\text { phase BIM model data }\end{array}$ & $S_{7-1}$ Insufficient data security \\
\hline
\end{tabular}

$\mathrm{S}_{8}$ Insufficient integrity of the BIM model for operation and maintenance management.

$\mathrm{S}_{9}$ Operation and maintenance management mode change.

$S_{10}$ The legal responsibility of the BIM model is unknown.

$S_{11}$ BIM technology is difficult $\quad S_{11-1}$ Technical applicability is not and insufficient for operation and high.

maintenance management.

$$
\begin{aligned}
& \mathrm{S}_{11-2} \mathrm{BIM} \text { is difficult to use in the } \\
& \text { operation and maintenance stage. } \\
& \mathrm{S}_{11-3} \text { The domestic BIM operation } \\
& \text { and maintenance system and } \\
& \text { management platform are } \\
& \text { insufficiently mature. }
\end{aligned}
$$

The long-term payback period of BIM technology investment, coupled with the high short-term investment cost of software and hardware of BIM technology, high personnel training and recruitment costs, leads to uncertain returns.

Relevant enterprises have insufficient investment in and determination to adopt BIM in the operation and maintenance stage.

BIM technology is not widely used in the operation and maintenance stage, and the industry experience is insufficient, and various companies and managers recognize BIM technology. And the degree of importance is different.

Employees are deficient in BIM knowledge and ability structure and lack relevant knowledge. Moreover, managers are accustomed to the traditional operation and maintenance work mode and avoid new technologies.

Lack of professionals familiar with BIM operation and maintenance management systems and platforms.

There is a certain degree of difficulty in model interaction between different software vendors, different stages, and different users, and it is easy to cause data loss in the process of model transfer. The storage security of BIM operation and maintenance model information of public infrastructure, and the security of data interaction is at risk.

The BIM model obtained from the previous stage cannot have all the information to satisfy the operation and maintenance.

From the traditional two-dimensional management mode to the use of BIM model technology for management, management personnel are not adapted to this mode.

The ownership of the BIM model in the operation and maintenance stage is not clear, the boundary of responsibility is unclear, and the setting of disputes and confidentiality mechanisms is lacking.

BIM technology is difficult to use in the operation and maintenance stage, which is quite different from the traditional operation and maintenance management mode; the domestic BIM operation and maintenance stage software technology is immature and lacks a more mature operation and maintenance system and management platform.

Note: Data in the table are derived from the summary in Table 1.

\subsection{Establish a Structural Self-Interaction Matrix}

In order to clarify the interaction relationship between various factors, semi-structured 
interviews were conducted with experts with rich BIM practical experience from the builder, the designer, the construction company and the university based on the above classification to determine the interaction relationship between factors. In order to avoid the experts being unable to form a unified opinion, the threshold value is set at $70 \%$, that is, as long as more than $70 \%$ of the experts believe that there is an influence between the two, the relationship is considered to be valid. The self-interaction matrix of the structure as shown in Figure 1 is finally established. "V" in the table indicates that row factor $S_{i}$ has influence on column factor $S_{j}$ "A" indicates that the column factor $S_{j}$ has an influence on the row factor $S_{i}$ " $\mathrm{X}$ " indicates that the row and column factors influence each other.

For example: column factor $S_{1}$ has a direct influence on row factors $S_{3}$ and $S_{9}$, so it is recorded as "A"; row factor $S_{11}$ has a direct influence on column factors $\mathrm{S}_{3}, \mathrm{~S}_{5}, \mathrm{~S}_{7}$, and $\mathrm{S}_{8}$, so it is recorded as "V"; column factor $\mathrm{S}_{4}$ and row factor $\mathrm{S}_{6}$, column factor $S_{1}$ and row $S_{5}$ have a mutual influence relationship, which is recorded as "X".

\subsection{Establish Adjacency Matrix and Reachability Matrix}

The adjacency matrix can visually represent the influence relationship between two elements. The adjacency matrix in this paper is based on the structural self-interaction matrix based on risk factors and follows the following rules: When $S_{i}$ has an influence relationship on $S_{j}$, the value of $a_{i j}$ is 1 , otherwise it is recorded as 0 . The adjacency matrix obtained after conversion is shown in Table 3.

The reachable matrix is based on the nature of Boolean matrix operations, which describes that one factor can affect another factor after passing a certain length of path. The influence relationship between BIM application risk factors in the operation and maintenance stage can be clearly described by solving the reachability matrix. The adjacency matrix A satisfies the condition $(A+I)^{(n-1)} \neq(A+I)^{n}=(A+I)^{(n+1)}=M$, then $M$ is the reachable matrix of the adjacency matrix $A$, Among them, $I$ is the identity matrix, and the calculation results are obtained through MATLAB programming. The results are shown in Table 4.

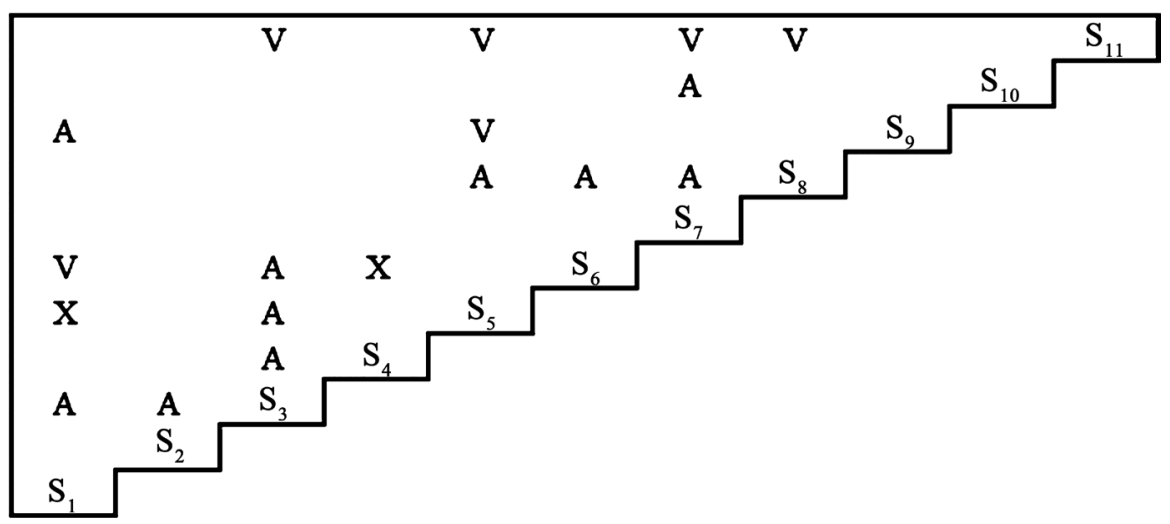

Figure 1. Self-interaction matrix diagram of risk factor structure of BIM application in the operation and maintenance phase. 
Table 3. Adjacency matrix A of risk factors of BIM application in the operation and maintenance stage.

\begin{tabular}{cccccccccccc}
\hline Risk factor & $\mathrm{S}_{1}$ & $\mathrm{~S}_{2}$ & $\mathrm{~S}_{3}$ & $\mathrm{~S}_{4}$ & $\mathrm{~S}_{5}$ & $\mathrm{~S}_{6}$ & $\mathrm{~S}_{7}$ & $\mathrm{~S}_{8}$ & $\mathrm{~S}_{9}$ & $\mathrm{~S}_{10}$ & $\mathrm{~S}_{11}$ \\
\hline $\mathrm{S}_{1}$ & 0 & 0 & 1 & 0 & 1 & 0 & 0 & 0 & 1 & 0 & 0 \\
$\mathrm{~S}_{2}$ & 0 & 0 & 1 & 0 & 0 & 0 & 0 & 0 & 0 & 0 & 0 \\
$\mathrm{~S}_{3}$ & 0 & 0 & 0 & 1 & 1 & 1 & 0 & 0 & 0 & 0 & 0 \\
$\mathrm{~S}_{4}$ & 0 & 0 & 0 & 0 & 0 & 1 & 0 & 0 & 0 & 0 & 0 \\
$\mathrm{~S}_{5}$ & 1 & 0 & 0 & 0 & 0 & 0 & 0 & 1 & 0 & 0 & 0 \\
$\mathrm{~S}_{6}$ & 1 & 0 & 0 & 1 & 0 & 0 & 0 & 1 & 0 & 0 & 0 \\
$\mathrm{~S}_{7}$ & 0 & 0 & 0 & 0 & 0 & 0 & 0 & 1 & 0 & 1 & 0 \\
$\mathrm{~S}_{8}$ & 0 & 0 & 0 & 0 & 0 & 0 & 0 & 0 & 0 & 0 & 0 \\
$\mathrm{~S}_{9}$ & 0 & 0 & 0 & 0 & 1 & 0 & 0 & 0 & 0 & 0 & 0 \\
$\mathrm{~S}_{10}$ & 0 & 0 & 0 & 0 & 0 & 0 & 0 & 0 & 0 & 0 & 0 \\
$\mathrm{~S}_{11}$ & 0 & 0 & 1 & 0 & 1 & 0 & 1 & 1 & 0 & 0 & 0 \\
\hline
\end{tabular}

Note: The data of matrix A is obtained through the transformation of structural self-interaction matrix diagram.

Table 4. The achievable matrix $\mathrm{M}$ of BIM application risk factors in the operation and maintenance stage.

\begin{tabular}{cccccccccccc}
\hline Risk factor & $\mathrm{S}_{1}$ & $\mathrm{~S}_{2}$ & $\mathrm{~S}_{3}$ & $\mathrm{~S}_{4}$ & $\mathrm{~S}_{5}$ & $\mathrm{~S}_{6}$ & $\mathrm{~S}_{7}$ & $\mathrm{~S}_{8}$ & $\mathrm{~S}_{9}$ & $\mathrm{~S}_{10}$ & $\mathrm{~S}_{11}$ \\
\hline $\mathrm{S}_{1}$ & 1 & 0 & 1 & 1 & 1 & 1 & 0 & 1 & 1 & 0 & 0 \\
$\mathrm{~S}_{2}$ & 0 & 1 & 1 & 1 & 1 & 1 & 0 & 0 & 0 & 0 & 0 \\
$\mathrm{~S}_{3}$ & 1 & 0 & 1 & 1 & 1 & 1 & 0 & 1 & 0 & 0 & 0 \\
$\mathrm{~S}_{4}$ & 1 & 0 & 0 & 1 & 0 & 1 & 0 & 1 & 0 & 0 & 0 \\
$\mathrm{~S}_{5}$ & 1 & 0 & 1 & 0 & 1 & 0 & 0 & 1 & 1 & 0 & 0 \\
$\mathrm{~S}_{6}$ & 1 & 0 & 1 & 1 & 1 & 1 & 0 & 1 & 1 & 0 & 0 \\
$\mathrm{~S}_{7}$ & 0 & 0 & 0 & 0 & 0 & 0 & 1 & 1 & 0 & 1 & 0 \\
$\mathrm{~S}_{8}$ & 0 & 0 & 0 & 0 & 0 & 0 & 0 & 1 & 0 & 0 & 0 \\
$\mathrm{~S}_{9}$ & 1 & 0 & 0 & 0 & 1 & 0 & 0 & 1 & 1 & 0 & 0 \\
$\mathrm{~S}_{10}$ & 0 & 0 & 0 & 0 & 0 & 0 & 0 & 0 & 0 & 1 & 0 \\
$\mathrm{~S}_{11}$ & 1 & 0 & 1 & 1 & 1 & 1 & 1 & 1 & 0 & 1 & 1 \\
\hline
\end{tabular}

Note: The data of achievable matrix M is obtained by calculation.

\subsection{Hierarchy and Determine the Hierarchical Structure}

According to certain rules, the risk factors in the reachable matrix $\mathrm{M}$ can be divided into different levels, so as to clearly show the influence and the relationship between the risk factors. The reachable set of risk factors $S_{i}$ is the set of risk factors reachable by $S_{i}$ in the reachability matrix, denoted as $R\left(S_{i}\right)$;

The antecedent set of risk factors $S_{i}$ is the set of risk factors that can reach $S_{i}$ in the reachability matrix, denoted as $A\left(S_{i}\right)$;

The common set is the intersection of the antecedent set and the reachable set, denoted as $C\left(S_{i}\right)$. 
The risk factor hierarchy is divided according to the following steps: First, the reachability set $R\left(S_{i}\right)$, the prior set $A\left(S_{i}\right)$ and the common set $C\left(S_{i}\right)$ of each factor are calculated through the reachability matrix. Then through $R\left(S_{i}\right)=C\left(S_{i}\right)$, the risk factors of this level are determined, and then the level factors are removed and the second calculation is performed until the level of all factors is determined. The calculation process and results are shown in Table 5.

According to the above calculations, the risk factors of the application of BIM in the operation and maintenance phase of the construction project are divided into four levels, namely $\mathrm{L} 1=\left\{\mathrm{S}_{8}, \mathrm{~S}_{10}\right\} ; \mathrm{L} 2=\left\{\mathrm{S}_{1}, \mathrm{~S}_{4}, \mathrm{~S}_{5}, \mathrm{~S}_{7}, \mathrm{~S}_{9}\right\} ; \mathrm{L} 3=\left\{\mathrm{S}_{3}, \mathrm{~S}_{6}\right\} ; \mathrm{L} 4=$ $\left\{S_{2}, S_{11}\right\}$. The interpretative structural model drawn according to the results is shown in Figure 2.

Table 5. Process table of the classification of risk factors.

\begin{tabular}{|c|c|c|c|c|}
\hline$S_{i}$ & $A\left(S_{i}\right)$ & $R\left(S_{i}\right)$ & $C\left(S_{i}\right)$ & $C\left(S_{i}\right)=R\left(S_{i}\right)$ \\
\hline 1 & $1,3,4,5,6,9,11$ & $1,3,4,5,6,8,9$ & $1,3,4,5,6,9$ & \\
\hline 2 & 2 & $2,3,4,5,6$ & 2 & \\
\hline 3 & $1,2,3,5,6,11$ & $1,3,4,5,6,8$ & $1,3,5,6$ & \\
\hline 4 & $1,2,3,4,6,11$ & $1,4,6,8$ & $1,4,6$ & \\
\hline 5 & $1,2,3,5,6,9,11$ & $1,3,5,8,9$ & $1,3,5,9$ & \\
\hline 6 & $1,2,3,4,6,11$ & $1,3,4,5,6,8,9$ & $1,3,4,6$ & \\
\hline 7 & 7,11 & $7,8,10$ & 7 & \\
\hline 8 & $1,3,4,5,6,7,8,9,11$ & 8 & 8 & $\sqrt{ }$ \\
\hline 9 & $1,5,6,9$ & $1,5,8,9$ & $1,5,9$ & \\
\hline 10 & $7,10,11$ & 10 & 10 & $\sqrt{ }$ \\
\hline 11 & 11 & $1,3,4,5,6,7,8,10,11$ & 11 & \\
\hline 1 & $1,3,4,5,6,9,11$ & $1,3,4,5,6,9$ & $1,3,4,5,6,9$ & $\sqrt{ }$ \\
\hline 2 & 2 & $2,3,4,5,6$ & 2 & \\
\hline 3 & $1,2,3,5,6,11$ & $1,3,4,5,6$ & $1,3,5,6$ & \\
\hline 4 & $1,2,3,4,6,11$ & $1,4,6$ & $1,4,6$ & $\sqrt{ }$ \\
\hline 5 & $1,2,3,5,6,9,11$ & $1,3,5,9$ & $1,3,5,9$ & $\sqrt{ }$ \\
\hline 6 & $1,2,3,4,6,11$ & $1,3,4,5,6,9$ & $1,3,4,6$ & \\
\hline 7 & 7,11 & 7 & 7 & $\sqrt{ }$ \\
\hline 9 & $1,5,6,9$ & $1,5,9$ & $1,5,9$ & $\sqrt{ }$ \\
\hline 11 & 11 & $1,3,4,5,6,7,11$ & 11 & \\
\hline 2 & 2 & $2,3,6$ & 2 & \\
\hline 3 & $2,3,6,11$ & 3,6 & 3,6 & $\sqrt{ }$ \\
\hline 6 & $2,3,6,11$ & 3,6 & 3,6 & $\sqrt{ }$ \\
\hline 11 & 11 & $3,6,11$ & 11 & \\
\hline 2 & 2 & 2 & 2 & $\sqrt{ }$ \\
\hline 11 & 11 & 11 & 11 & $\sqrt{ }$ \\
\hline
\end{tabular}




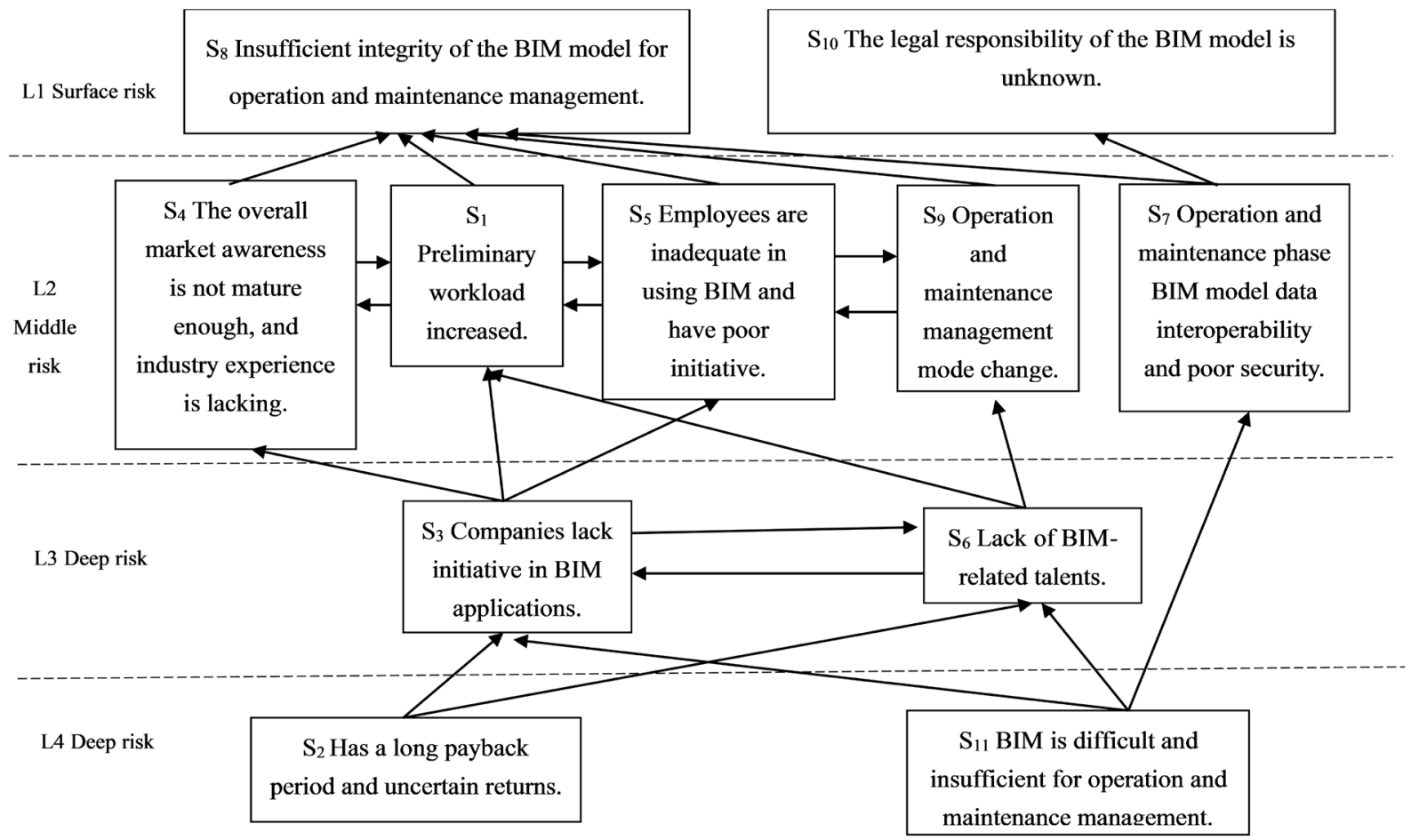

Figure 2. ISM diagram of BIM application risk factors in the operation and maintenance phase.

\subsection{ISM Model Analysis}

According to the construction project operation and maintenance phase BIM application risk factor interpretative structural model diagram, the established ISM model diagram is a 4-level hierarchical model. In order to explain the relationship between risk factors more clearly, the ISM hierarchy diagram is divided into three levels, namely, the deep risk factors are L3 and L4, the middle risk factors are L2, and the surface risk factors are L1.

Deep-level risk factors affect middle-level risk factors and surface-level risk factors through transmission paths.

The superficial risk factors in the model are " $\mathrm{S}_{8}$ Insufficient integrity of the BIM model for operation and maintenance management." and " $\mathrm{S}_{10}$ The legal responsibility of the BIM model is unknown." and the two risk factors have no mutual influence. This level of risk will have a direct impact on the application of BIM technology in the operation and maintenance phase of construction projects, which has delayed the promotion of BIM technology in the operation and maintenance phase to a certain extent, but the surface risk factors are affected by deep and middle risk factors. The risk of surface risk factors is relatively low.

There are four risk factors at the middle level in the model, and there are interrelationships between the risk factors. The insufficient ability of enterprise employees will lead to the increase of the workload in the early stage of BIM application in the operation and maintenance stage, which will lead to the poor initiative of employees to apply BIM, highlighting the insufficient ability of em- 
ployees and the change of enterprise management mode, and will also lead to the low market popularity. Therefore, there is a mutual influence relationship between risk factors at this level.

Risk factors at this level have an indirect effect on the application of BIM technology in the operation and maintenance phase of construction projects, and have the function of risk transmission, and affect the entire system by transmitting the effects of deep risk factors to surface risk factors. For example, due to the poor initiative of enterprises to adopt BIM technology, the market popularity of BIM is not high, which in turn affects the integrity of the model in the operation and maintenance phase.

The deep risk factors in the model include " $\mathrm{S}_{3}$ Companies lack initiative in BIM applications", " $\mathrm{S}_{6}$ Lack of BIM-related talents", " $\mathrm{S}_{2}$ Has a long payback period and uncertain returns" and " $\mathrm{S}_{11} \mathrm{BIM}$ is difficult and insufficient for operation and maintenance management", and there is an interactive relationship between $\mathrm{S}_{3}, \mathrm{~S}_{6}$.

The risk factors at this level are the root risk factors that affect the application of BIM in the operation and maintenance phase of the construction project, and they are the root causes of middle-level and surface-level risks. To solve the key risk of BIM application in the operation and maintenance stage is to manage and handle the deep risk factors reasonably.

\section{Suggestions}

1) In terms of financial risks, the main problem is that the application of BIM technology in the operation and maintenance phase requires the application of BIM in the early design and construction phases, which will cause short-term cost increase, long investment recovery period, and uncertain returns. In addition, the investment in BIM technology's software and hardware supporting measures is also relatively high. In this regard, the way companies should take is first to get the support of national policies. The second is to extensively contact various BIM companies and platforms, strengthen cooperation and exchanges, enhance the company's own BIM technology secondary development capabilities, and form products with some independent intellectual property rights, improve design and construction efficiency, and improve operation and maintenance management capabilities, and reduce Cost, reduce or eliminate financial risks. Finally, the investment payback period is extended, with a long-term view, and BIM technology can also be used throughout the life cycle of the construction project. All parties who adopt BIM technology share the costs incurred and reduce financial risks.

2) Enterprises should increase their initiative in applying BIM technology. First of all, enterprise leaders should pay more attention to the application of BIM in the operation and maintenance stage as well as the preliminary construction and design stage, formulate long-term plans and goals, prevent the emergence of single-stage BIM application, lack of efficient transmission, resulting in 
the effect of BIM on the enterprise is not obvious. Secondly, relevant personnel of the enterprise need to enhance the awareness of BIM use. At present, due to the inherent working mode, organizational structure, work ability assessment standards and other reasons, the enterprise staff's awareness of BIM application is weak. Enterprises can develop promotion mechanisms and incentives for BIM compliant personnel from top to bottom to enhance the initiative of all employees to apply BIM, so as to increase the internal motivation of the enterprise itself to apply BIM.

3) At this stage, as a technical tool, BIM technology has been widely used in the construction phase. Its visualization, collision inspection, electromechanical deepening, and bidding program simulation have been implemented and generally recognized, but the application in the operation and maintenance phase is still in the process of exploring. At this stage, it is necessary to integrate software and develop BIM products suitable for operation and maintenance, and consider the "applicability" of the product. Thereby improving the applicability of BIM in the operation and maintenance phase of construction projects, reducing the difficulty of use, and improving the maturity of BIM applications.

4) Lack of talent is a problem faced by all walks of life, especially for the application of a new technology. The solution to the lack of talents are external recruitment and internal training. The personnel in the BIM operation and maintenance stage must first understand BIM technology and also need to have previous overall work experience. For fresh graduates, they lack the experience brought by actual business, and they need certain project opportunities to gain experience in order to become qualified BIM personnel; For internal employees, due to their inherent thinking mode and work process, there is a certain degree of rejection of new technologies, and it is necessary to conduct special BIM training for them and develop a reasonable promotion mechanism and salary system for them. In addition, the project can hire a third-party professional BIM organization to provide services.

\section{Summary}

With the domestic concepts of "Built in China" and "Digital China" being put forward, the promotion of BIM technology in my country has also received attention. At this stage, the application of BIM technology is more concentrated in the construction stage, but the BIM concept plays an increasingly important role in the construction operation and maintenance stage. Because it well inherits the concept of the BIM life cycle, the results of the BIM model in the design and construction phases are used to improve the efficiency of operation and maintenance management while reducing costs.

The article analyzes the risk factors of applying BIM technology in the operation and maintenance phase, summarizes through literature review, and then makes corrections through expert interviews, and finally analyzes the risk factors through the establishment of a hierarchical interpretative structural model. 
The study found that the four deep-seated risk factors include "Companies lack initiative in BIM applications", "Lack of BIM-related talents", "Has a long payback period and uncertain returns" and "BIM is difficult and insufficient for operation and maintenance management". Then the writer puts forward relevant improvement suggestions, hoping to provide relevant ideas for the application of BIM in the construction operation and maintenance phase.

However, this paper only focuses on the analysis of risk factors of BIM application in the operation and maintenance stage, and the data obtained by expert interview and semi-structured interview adopted in this paper have certain subjective factors. In the future research, objective data can be obtained by other means or other models can be used to analyze the risk factors of BIM application in the operation and maintenance stage, and certain examples can be taken for verification.

\section{Fund Project}

Research on Integrated Management of Engineering Cost Based on BIM Technology (Zigong Science and Technology Bureau 2013D12).

\section{Conflicts of Interest}

The authors declare no conflicts of interest regarding the publication of this paper.

\section{References}

Azhar, S. (2011). Building Information Modeling (BIM): Trends, Benefits, Risks, and Challenges for the AEC Industry. Leadership \& Management in Engineering, 11, 241-252. https://doi.org/10.1061/(ASCE)LM.1943-5630.0000127

Bernstein, P. G., \& Pitman, J. H. (2005). Barriers to the Adoption of Building in formation Modeling in the Building Industry. Autodesk Building Solutions Whitepaper, 10, 231-241.

Chen, J. Y., Ding, J., Zheng, W., \& Chen, F. (2017). Study on the Risk of BIM Technology Application in Shanghai Planetarium Project. Project Management, No. 10, 61-64.

Chen, Q. (2012). BIM Adoption Risk Study in Building Design Project. Civil Engineering Information Technology, 4, 22-31.

Chien, K. F., Wu, Z. H., \& Huang, S. C. (2014). Identifying and Assessing Critical Risk Factors for BIM Projects: Empirical Study. Automation in Construction, 45, 1-15. https://doi.org/10.1016/j.autcon.2014.04.012

Ding, X. X., \& Wang, J. J. (2016). Risk of Proprietor in Construction Projects Based on BIM. Journal of Jilin Jianzhu University, 33, 97-100.

Eadie, R., Odeyinka, H., Browne, M., McKeown, C., \& Yohanis, M. (2014). Building Information Modelling Adoption: An Analysis of the Barriers to Implementation. Journal of Engineering and Architecture, 2, 77-101.

Eastman, C., Eastman, C. M., Teicholz, P. et al. (2011). BIM Handbook: A Guide to Building Information Modeling for Owner, Manager, Designer, Engineers and Contractors (p. 243). Hoboken, NJ: John Wiley \& Sons.

Feng, S. G., Chen, G. C., \& Li, Q. M. (2019). BIM Application Risks and Contract Coun- 
termeasures in Engineering Projects: A Study from the Perspective of Owners. Journal of Engineering Management, 33, 116-120.

Guo, L. (2015). Risk Identification and Responses of BIM-Application in Construction Projects. Construction Economy, 36, 30-34.

Hu, S. J., Xu, B., \& Wang, J. P. (2018). Research on Risk Factors Affecting the Application of BIM Technology in Construction Enterprises. China Real Estate, No. 15, 65-73.

Hu, Z. Z., Peng, Y., \& Tian, P. L. (2015). A Review for Researches and Applications of BIM-Based Operation and Maintenance Management. Journal of Graphics, 36, 802-809.

Li, M. M., Lai, J. Y., Chen, Q. L., Yi, Z. N., \& Sun, X. D. (2018). Application Risk Evaluation of BIM Technology Based on SEM. Journal of Chongqing University of Technology (Natural Science), 32, 206-212.

Li, Y. W. (2016). Research on Risk Assessment of BIM Application in Construction Project. Chongqing: Chongqing University.

Liang, Z. F. (2020). Tianjian Tianjiao Project BIM Technology + Management Application Practice. Information of China Construction, No. 24, 42-47.

Liu, J. K., Liu, J. C., Wang, D., \& Zhu, J. (2018). An Analysis of BIM Construction Project Risks Using the DEMATEL Model. Journal of Guangdong University of Technology, 35, 72-78.

Meng, N. (2017). Four Key Words to Interpret the Digital Transformation of the Construction Industry. Architecture, No. 14, 18-21.

Qin, X., Mancini, M., Travaglini, A., Lv, K. C., \& Wang, M. (2016). A Comparative Study on Barriers between China and Italy in BIM Adoption from the Construction Market Perspective. Journal of Management, 13, 1718-1727.

Taylan, O., Bafail, A. O., Abdulaal, R. M. S., \& Kabli, M. R. (2014). Construction Projects Selection and Risk Assessment by Fuzzy AHP and Fuzzy TOPSIS Methodologies. Applied Soft Computing, 17, 105-116. https://doi.org/10.1016/j.asoc.2014.01.003

Tian, J. C. (2018). Research on Risk Assessment of BIM Application in Construction Projects. Jinan: Shandong Jianzhu University.

Tong, Z., \& Wang, D. B. (2014). Research on the Application of BIM in the Operation and Maintenance Management of Commercial Real Estate Projects. China Housing Facilities, No. 7, 98-98.

Wang, D. (2015). Research on the Risk Management of BIM Application Projects. Xi'an: Xi'an University of Architecture and Technology.

Wang, J., Zhang, Y. Y., Wang, X. C., Yu Bo, Zhou, F. P., \& Wang, J. Y. (2019). Research on Barriers to BIM Data Sharing under the Owner-Driven Mode. Journal of Engineering Management, 33, 36-41.

Xie, X., Qin, X., \& Wang, F. H. (2018). Study on Establishment and Evaluation of Risk Network in BIM Technology Based on Owners' Side. Journal of Huaqiao University (Natural Science Edition), 39, 37-42.

$\mathrm{Xu}$, H. Y. (2020). Application of BIM Technology in the Subway Construction Schedule Risk Management. Value Engineering, 39, 224-226.

Xu, J., Li, A. H., Liu, H. Q., Ye, M. Z., \& Zhang, J. R. (2014). Application and Risk Analysis of BIM in Railway Systems. Journal of Railway Engineering Society, No. 3, 129-133.

$\mathrm{Xu}$, M. L., \& Xiong, F. (2014). The Study of BIM Risk in Application Phrase. Construction Technology, 43, 526-531.

Yang, J. G. (2017). Research on the Application of BIM Technology in Project Cost Risk 
Management. China High-Tech Enterprises, No. 9, 54-55.

Yu, Y., Wang, W., Shi, L. Y., \& Wang, Y. H. (2018). Application of BIM Technology in Longhu Financial Center Project. Construction Safety, 33, 55-57.

Zhang, H., Zu, P. X., Li, Y. F., \& He, Q. (2016). Research on the Application of BIM Technology Based on Structural Equation. Journal of Engineering Management, 30, 40-44.

Zhang, J., Zhang, Y. B., \& Shen, W. (2017). Analysis of BIM Risk Factors for Construction Enterprises Based on AHP-A Case Study of Tianjin Goldin Finance 117 Building Project. Journal of Beijing University of Civil Engineering and Architecture, 33, 69-75.

Zhu, P. H., \& Fu, R. (2020). Application of BIM Technology in Water Supply and Drainage Engineering Design-A Case Study of Baishishan Geological Museum in Baoding, Hebei Province. Jiangxi Building Materials, No. 4, 75-76. 